\title{
Application of GIS in General Soil Mapping of Bangladesh
}

\author{
Md. Azharul Islam*, Md. Amit Hasan, Murad Ahmed Farukh \\ Department of Environmental Science, Faculty of Agriculture, Bangladesh Agricultural University, Mymensingh, Bangladesh \\ Email: *maislam@bau.edu.bd
}

How to cite this paper: Islam, Md.A., Hasan, Md.A. and Farukh, M.A. (2017) Application of GIS in General Soil Mapping of Bangladesh. Journal of Geographic Information System, 9, 604-621.

https://doi.org/10.4236/jgis.2017.95038

Received: August 24, 2017

Accepted: October 28, 2017

Published: October 31, 2017

Copyright (c) 2017 by authors and Scientific Research Publishing Inc. This work is licensed under the Creative Commons Attribution International License (CC BY 4.0).

http://creativecommons.org/licenses/by/4.0/

\begin{abstract}
Bangladesh is a densely populated country where food crisis is one of the major issues where proper soil mapping is lacking till now. The purpose of this study is to prepare soil mapping of Bangladesh including different soil factors like $\mathrm{pH}$, salinity, nutrients, texture, porosity, toxicity etc., along with general soil types and land availability through application of Geographical Information System (GIS). Q-GIS software and secondary data are used in this study. In present study, it was found that 12 types of soil texture were present in all around of Bangladesh and the maximum percentage of soil porosity values varied from $20 \%$ to $70 \%$. A medium range of soil organic matter and strongly acidic soil was found all around the Bangladesh. It was found that the southern part of Bangladesh had slightly saline to highly saline soil. The major part of Bangladesh had medium high land which is very much preferable to agriculture. In Bangladesh, three categories of land such as highland, medium highland and low land cover $29 \%, 35 \%$ and $21 \%$ of total land, respectively. Agriculture land covers 9.5 million hectares in Bangladesh. The shifting rate based on agricultural use had been reported to be about $1 \%$ per year. At present, the amount of forest land covers $9.84 \%$ of total land of our country but 1976 it was $12.11 \%$. Mangrove is now at $4.07 \%$ of total land mass of our country. In generally, 20 types of soils were found all around the country. Mapping of soil types described these 20 general soil types under 5 main categories and these are calcareous soil, non-calcareous soil, terrace soil, gray soil, peat and hill soils. This study will be helpful for the cultivator to cultivate appropriate crops in appropriate places after exploration at a glance.
\end{abstract}

\section{Keywords}

GIS, Soil Mapping, Soil Type, Bangladesh

\section{Introduction}

Bangladesh is an agro-based country where soil classification and their using 
pattern are the important parts for researchers and farmers also. Many researchers now agree that land use should require a two-way link between land and environmental conditions. So, land use needs to be developed in a planned way and Geographical Information System (GIS) can play an important role in decision making with this planning process [1]. The application of GIS is limited in land use but recently it has been used for land classification, surveying land, mapping land, facility monitoring, and visual resource assessment and identifying suitable areas for developing agricultural activities etc. [2]. The use of GIS plays an important role in land classification. In general, these geospatial technologies provide efficient tools to store manipulate and analyze a great variety of spatial data. More specifically, it can be used to produce map where land covers and monitor landscape changes in respect of time [3].

Bangladesh has a wider range and greater complexity of lands. The soils of Bangladesh are divided into seven tracts, 20 general soil types and 537 soil series. At present, the soils of Bangladesh are divided into thirty Agro-ecological zones, thirty percent coastal areas present in Bangladesh. Out of, which 2.85 million hectares are coastal and off-shore areas are about 0.833 million hectares arable lands, which constitute about $52.8 \%$ of the net cultivable area and it is affected by varying degrees of soil salinity [4]. It is almost impossible to make a quick and suitable planning decision without utilizing support of any technology. GIS can assist in a huge range of applications including land use and land classification because of its large capacity. The major importance of this research is to demonstrate the use of GIS in land classification based on present status and future planning. For proper land use, classification and its patterns, future agricultural planning and ways of management of soils, the status of physical and chemical properties of soils has significant importance [5]. In this regards, different previously published reports will be emphasized and accommodated to explore the conditions of different soil utilization.

Bangladesh is endowed with a favorable climate and soil conditions for the production of a variety of crops all the year round. Thus, there are ample opportunities for crop. For various types of crop production, the consideration of sustainability, productivity, efficiency, effectiveness, zoning, timing are the important component to adopt farming decisions in order to meet the food demand of the country. Bangladesh is affected almost every year by numerous natural hazards like floods, cyclone, river bank erosion, tornedo, drought, thunderstorm etc. which directly and indirectly affect on the agricultural production, human health and environment. For this purpose it needs to monitor soil utilization pattern, types of soils, crop growth and development, land evaluation [6]. In modern era, GIS is an important digital tool for helping such research and findings. But there are very much limited using GIS on different aspect of Bangladesh rather than status of drinking water [7]. GIS mapping related research activities in Bangladesh is still unknown. The main purpose of the study is to explore the soil types based on present using, and future planning for resources 
management using GIS. The specific objectives are to describe and display the important properties of soil in Bangladesh and to visualize at a glance the present status of land types, land use and general soil classification over Bangladesh through QGIS.

\section{Materials and Methods}

\subsection{Study Area}

The study was conducted in Bangladesh lies in between $20.70^{\circ}$ and $26.80^{\circ}$ north latitudes and $88.01^{\circ}$ and $92.75^{\circ}$ east longitudes.

\subsection{Study Period}

This study was performed from January, 2015 to May, 2017.

\subsection{Data Collection}

In order to fulfill the objectives for this study pertinent information and literature were collected from different sources. The major portion of this study data was collected as secondary data sources, like-Bangladesh Agricultural Research Council (BARC), Soil Resource Development Institute (SRDI), published journals etc. Shape files of soil texture, soil porosity, soil organic matter, soil $\mathrm{pH}$, soil nutrients, soil toxicity, soil salinity and various types of important data were provided by Bangladesh Agricultural Research Council. On the other hand, various important data and result of various analyses such as availability of agriculture land, forest land, inundation land, mangrove, rivers network, general soil types etc. were provided by Soil Resource Development Institute (SRDI). Literature about the relevant research was collected from the internet and various journals.

\subsection{Data Input and Analysis}

For data processing, analyzing and map production QGIS 2.4.0 software had been used. The core engine of QGIS is coded in $\mathrm{C}++$, but additional QGIS plugging were written in the scripting language "Python". In this study, author had used ESRI shape files (polygons, points and line or polylines) and Bangladesh Transverse Mercator System. The shape file is a popular geospatial vector data format for geographic information system GIS software. The Bangladesh Transverse Mercator System (BTM) has used as the coordinate system which is an area specific standard UTM projection system for Bangladesh. In the map, colors were used to identify the existing land cover features.

\subsection{Data Analysis and Presentation}

Obtained data (secondary data and shape files) were recorded on Microsoft Office Excel 2010 spreadsheets. Obtained data were compiled, then tabulated and analyzed for securing different objectives relevant to studied parameters. The produced maps of related parameters were represented accordingly with proper 
discussion and comparison. Color ramping indicates the variation among the availability based on location of the country.

\section{Results and Discussion}

\subsection{Physical and Chemical Properties of Soil Mapping}

\subsubsection{Soil Texture}

In the present study, about 12 types of soil texture were present in all around of Bangladesh. Produced map of soil texture indicates that, clay soils were available in parts of Faridpur, Rajbari, Kustia, Madaripur and Shariyatpur district. Loam soils were found in some parts of Mymensingh, Sherpur and Tangail. Silt soils were found in some parts Noakhali and small parts of Chittagong districts. Sandy soils were found in some parts Cox's Bazar districts. Clay loam soils were found in some parts of Jessore, Kustia, Rajshahi, Bogra and Khulna. Silty loam soils were found in some parts of Barisal, Sylhet, Rangpur, Bogra, Tangail, Moulovibazar, Sunamgonj and Chittagong districts. Silty clay loam soils were found in some parts of Comilla, Feni and Munshigonj. Silty clay soils were found in some parts of Satkhira, Khulna, Bagerhat, Pirojpur, Borguna Potuakhali and Bhola district. Loamy sand were found in hill tracts of Bangladesh like Rangamati, Khagracharia and Bandarban districts. Sandy loam were found in some parts of Dhaka, Manikgonj, Gazipur, Narayangonj, Norshindhi and Rangpur district. Sandy clay loam was found in some parts of Panchagarh, Thakurgaogh, Dinajpur and some part of Nilphamari distrirts (Figure 1).

The soil of Barisal and Ghior series on Gangetic alluvium was silty clay to clay in texture [8]. However, the texture of Gangachara and Sonatala series of Tista and Brahmaputra alluvium were silt loam. In BAU farm soil, the percentage of sand, silt, clay varied from 17.00 to $19.00,59.00$ to 63.00 , and 22.00 to 21.00 respectively [9]. The silt content increased and clay content decreased with increasing depth while sand content first decreased to sub surface horizon and then increased with increasing depth in the soil of Madhupur tract [10]. The soil texture of the old Brahmaputra floodplain soil ranged from silt loam to clay, within the soil profile, large variation in proportion of sand, silt and clay content was obtained in different layers. Silt was dominant size fraction and sand was mostly in the form of very fine sand. The texture of soil profile affected other physical properties such as permeability, aeration, moisture retention etc. [11].

\subsubsection{Soil Porosity}

All types of porous soil found in all over the Bangladesh. It was revealed that, hill tract of Bangladesh including Rangamati, Khagrachari and Bandarban had a porosity level of $20 \%-30 \%$. Chittagong, Feni, Cox's Bazar, Barisal and Jhalokhati had a porosity level of $31 \%-40 \%$. Most of Bangladesh had a porosity level of $41 \%-50 \%$. The indigo colored portion indicates the porosity level of $41 \%-50 \%$ in figure below. It was found that, Sunamgonj, Hobigonj, Sylhet, Moulavibazar, Panchagorh, Thakurgaoun, Nilphamari, Dinajpur, Rangpur, Lalmonirhat, Kurigram, Gaibandah and Jamalpur had a porosity level of 51\%-60\%. Some part of 


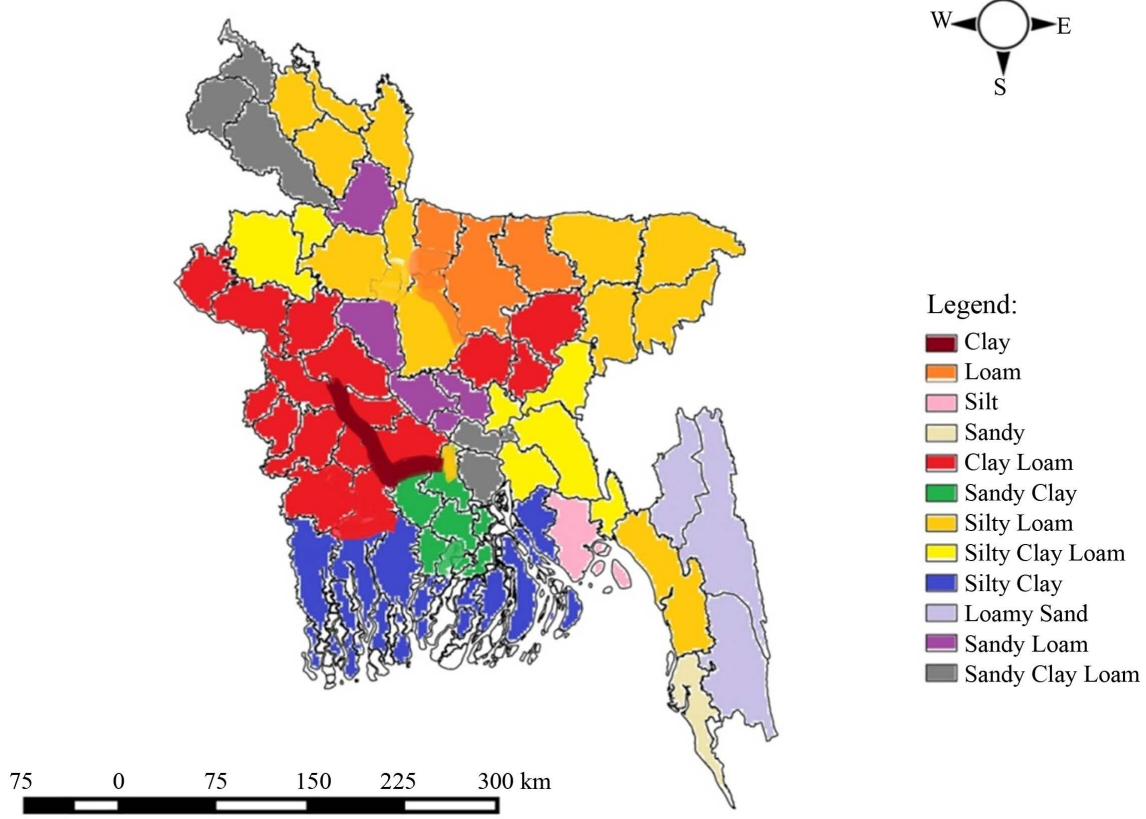

Figure 1. Categorizes of soil texture in Bangladesh.

Jheneidah, Meherpur, Khulna, Pirojpur, Borguna and Bhola had a porosity level of $61 \%-70 \%$ (Figure 2). The percentage of soil porosity values in BAU varied from 43.62 to 44.14 [9] (Azad, 2000). The total porosity ranged is 43 and 56.7 in the hilly soils of greater Sylhet district. Values of these parameters decreased with depth in all the profiles with a few exceptions. Total porosity had significant positive correlation with organic matter and organic plus clay pus silt plus sand [12]. The total porosity varied from $42 \%$ to $46 \%$ in the Barind tract and the total porosity ranged from $42 \%$ to $47 \%$ in Ganges floodplain soils [13].

\subsubsection{Soil Organic Matter}

Organic matter content soil was recorded in all over the Bangladesh with a variation of values. It was found that the soil of Gopalgonj, Madaripur and Barisal districts contained a very high amount of organic matter in this current research. The soil of Sylhet, Moulovibazar, Jessore and Narail districts had a high amount of organic matter. On the other hand, most parts of this country had medium amount of organic matter in its soil. The lawn green colored portion indicates medium level of organic matter of soil found in Bangladesh. However, the soil of Panchagarh, Thakurgaon, Rangpur, Gaibandha, Nababgonj, Meherpur, Jhenaidah, Narayangonj and Norshindhi districts had a low amount of organic matter. Thus, the soil of Satkhira, Khulna, Bagerhat, Rangamati, Bandarban, Khagrachari and Chittagong districts had a unique forest area that had an optimum organic matter (Figure 3).

The organic matter content varied from $0.58 \%$ to $2.13 \%$ of the BAU farm and also reported its content was relatively higher at the surface layer [14]. The organic carbon values varied from $0.40 \%$ to $2.54 \%$ in the salt-affected Rupsa thana 


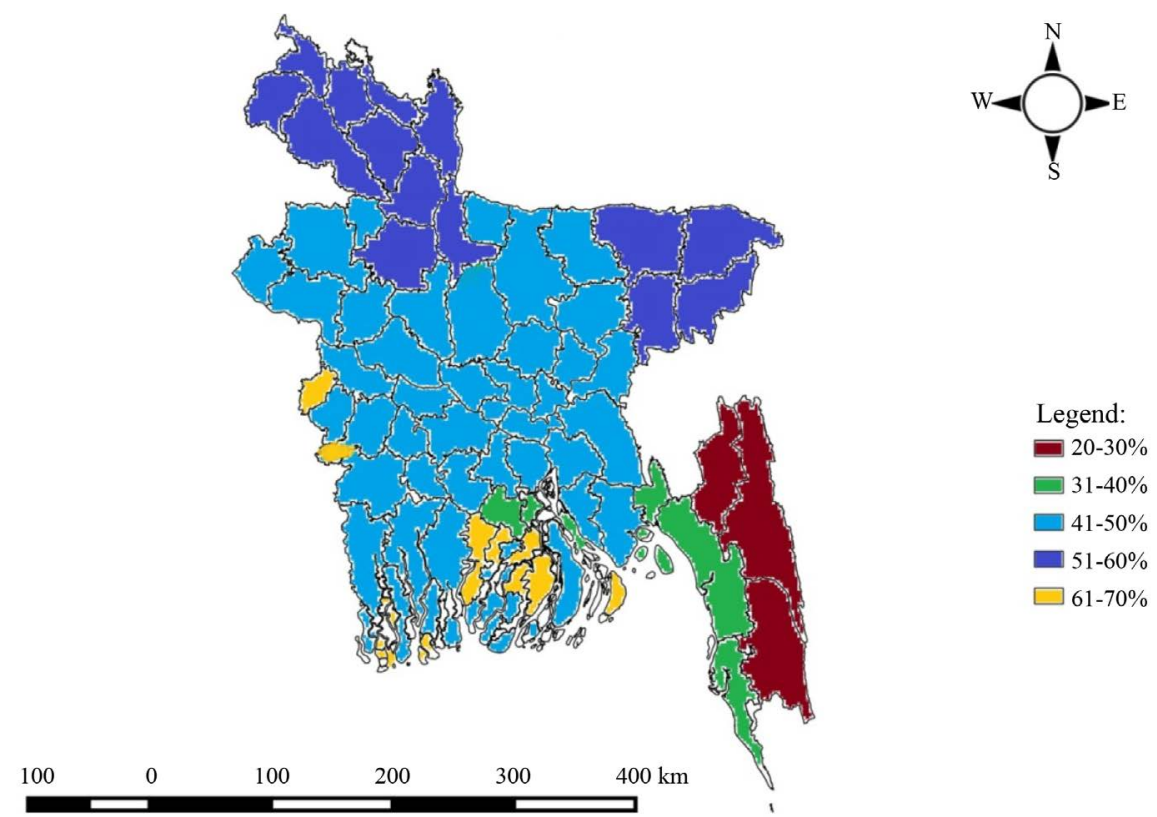

Figure 2. Level of soil porosity in Bangladesh.

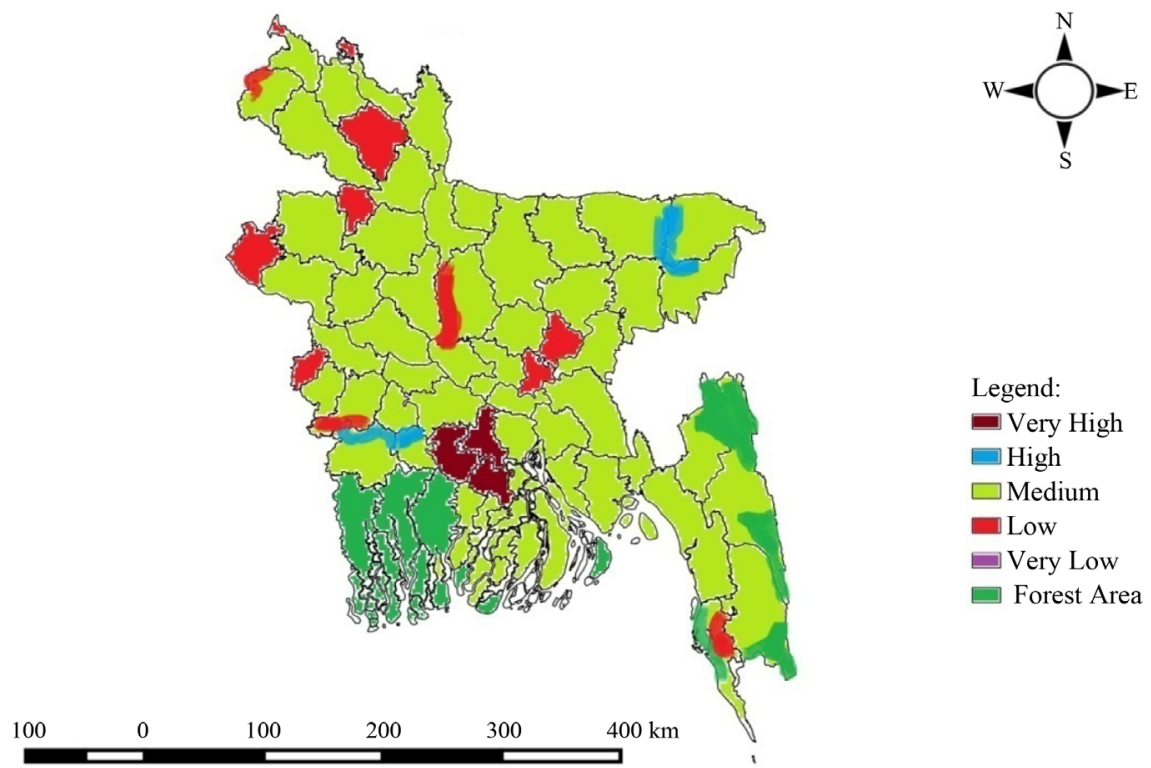

Figure 3. Organic matter status in the soil of Bangladesh.

soils of Khulna district and $0.51 \%$ to $0.64 \%$ in the areas of Patuakhali and Barguna districts of Bangladesh and the high value was observed at surface soil [15]. The organic carbon content decreased with depth in all the profiles with its content ranging from $0.03 \%$ to $1.58 \%$ [16], which is shown in the present study (Figure 3). Organic carbon of the Sundarbans mangrove soils decreased with depth in all the profiles with its content ranging from $0.29 \%$ to $0.89 \%$ [17]. The soils of Madhupur tract were in general low $(<2 \%)$ in organic matter content. Comparatively higher values were obtained in the irrigated areas than the nonirrigated areas [10]. The organic matter percent of different soil series of Ban- 
gladesh ranged from 0.86 to 4.99 and the mean organic matter per cent was 2.09 [18], which identical in present study (Figure 3). The organic matter content gradually decreased, reported in present study; which is similar with the increasing of soil depths and ranged from $0.33 \%$ to $1.59 \%$ [19].

\subsubsection{Soil pH}

Soil $\mathrm{pH}$ was categorized with its range and quality in Bangladeshi soil. In present study, it was found the soil of Sylhet, Sunamgonj, Netrokona, Moulovibazar and Hobigonj districts was extremely acidic. In this study, most of soil in Bangladesh was in a level of strongly acidic condition. The pink colored area in map indicated strongly acidic soil location found in Bangladesh. The soil of Kurigram, Rangpur, Dinajpur, Gaibandha, Joypurhat, Jamalpur, Sherpur, Kishorgonj, Mymensingh, B. Baria, Comilla, Chandpur, Noakhali, Feni, Gopalgoinj and Chittagong was highly acidic. The soil of south-western part of Bangladesh along with Kurigram, Gaibandah, Jamalpur, Sirajgonj and Tangail districts was neutral or around 7.0. Most of south-western part of Bangladesh was in the category of highly alkaline soil type (Figure 4). The $\mathrm{pH}$ of BAU farm soil ranged from 7.45 to 7.68 [9] and 6.66 to 7.47 [14]. The $\mathrm{pH}$ of Patuakhali and Barguna districts of Bangladesh varied from 6.21 to 7.88 and at some locations increased with the soil depths [20].

\subsubsection{Soil Salinity}

It was found that the soil of Khulna, Bagerhat, Satkhira, Barishal, Bhola, Jhalokhati, Borguna, Pirojpur, Potuakhali, Laxmipur, Chittagong, Noakhali, Cox's Bazar district had slightly saline to highly saline soil. The ranges of soil salinity are given below (Figure 5). Mostly the saline soils were observed at the southern parts of the country. Rest of the parts of Bangladesh none soil salinity occurred.

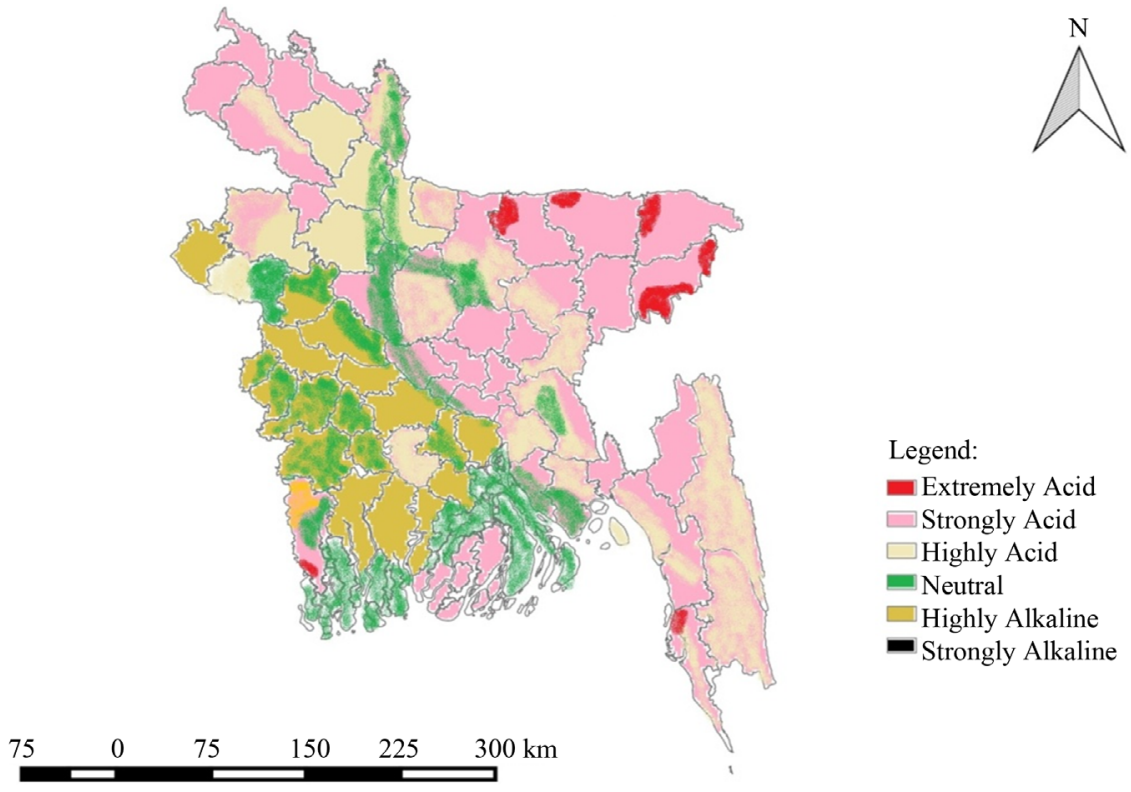

Figure 4. Soil pH status in Bangladesh. 


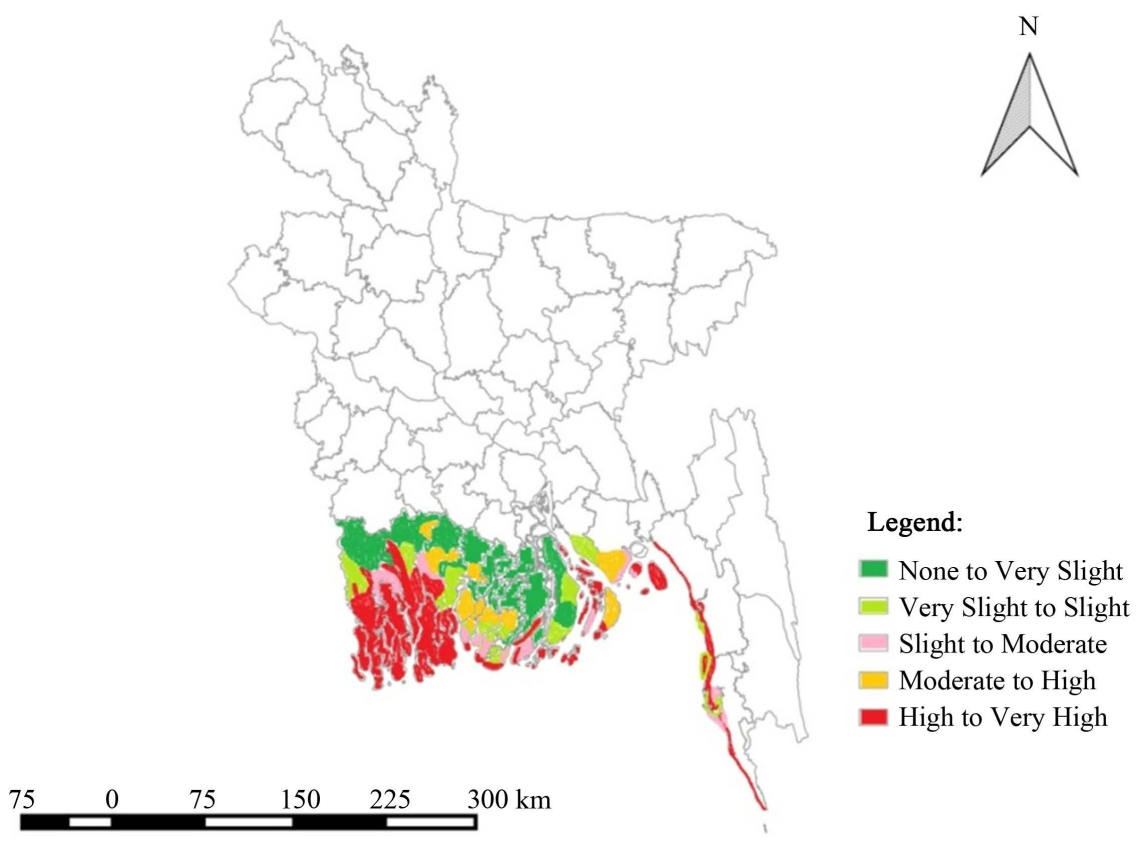

Figure 5. Salinity status in Bangladesh soils.

Around 5\% areas were saline soil in Barisal and Khulna districts [21], which is matched with present study in map (Figure 5).

\subsection{Inundation Land Types}

Bangladesh are classified into highland, medium highland and lowland based on the depth of flood levels usually. In this present study, it was illustrated in map about maximum areas of the districts of Chittagong hill tract and Bandarban were belongs to high land category. The second lowest area containing districts were Bogra, Jamalpur, Tangail and Dhaka. The third lowest area containing districts are Dinajpur, Rajshahi, Chittagong and Cox's Bazar. The fourth lowest area containing districts are Rangpur, Pabna, Mymensingh and Sylhet. Maximum areas of the districts of Faridpur, Kustia and Jessore were belongs to medium high land category. The second lowest area containing districts were Rangpur, Pabna and Mymensingh. The third lowest area containing districts were Dinajpur, Rajshahi, Chittagong and Cox's Bazar. The fourth lowest area containing districts were Jamalpur, Bogra, Tangail and Dhaka. In this current study, maximum area of the district of Barisal belongs to low land category and it was followed by Khulna and Sylhet. Second lowest area was found in Rangpur, Pabana, Mymensingh, Faridpur, Kustia and Jessore districts (Figure 6). In Bangladesh highland, medium highland and low land cover $29 \%, 35 \%$ and $21 \%$ of total land respectively. Others $15 \%$ land covers by river, urban and homesteads etc. [22]. About $99 \%$ areas of the Chittagong hill tract and Bandarban were belonging to high land category. Faridpur, Kustia and Jessore districts has shown that it contains about $80 \%$ of medium high land in its area. On the other hand, among the districts of low land category only Barisal districts had covered its 


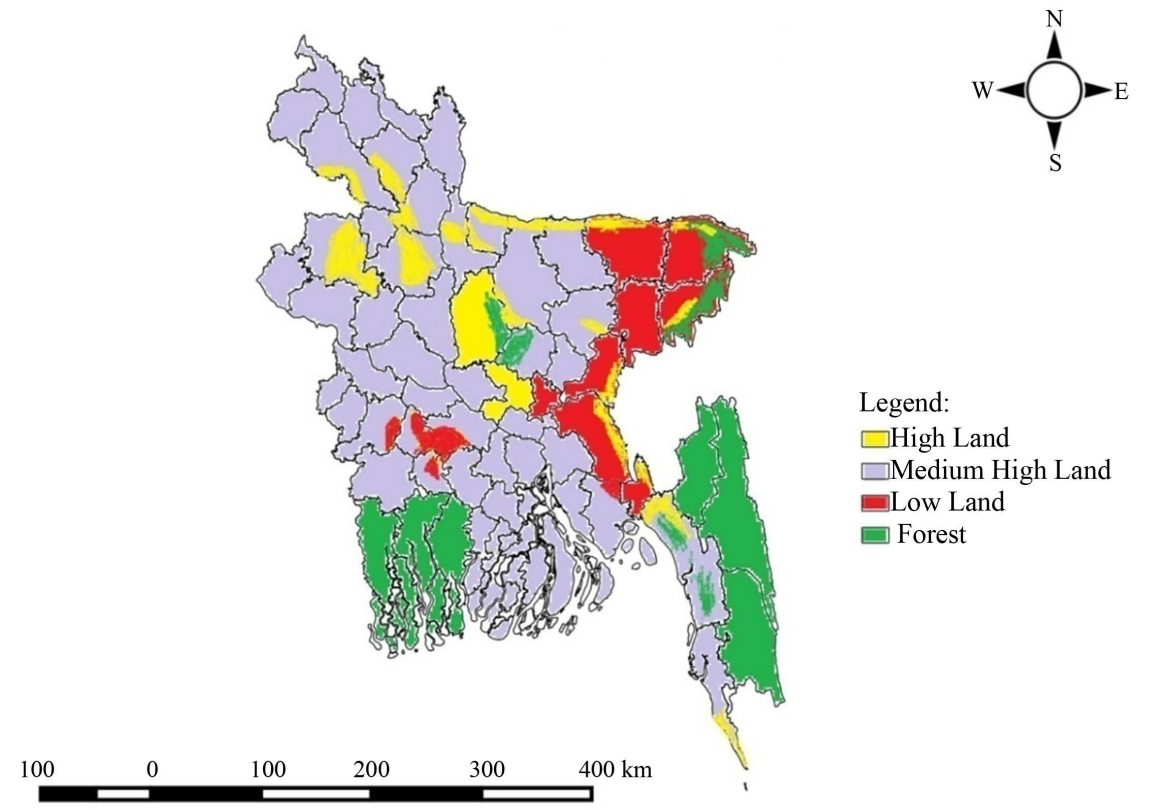

Figure 6. Showing the categories of land in the Bangladesh using Q-GIS mapping.

$90 \%$ area by low land (Figure 6).

\subsection{Land Availability in Bangladesh}

\subsubsection{Agricultural Land}

It was found that most part of Bangladesh consist of agricultural land. But hill tract and sundarban regions were out of agricultural zone because of high salinity and altitude (Figure 7). Agricultural land included crop land, forest, mangrove forest, river, lake, beel, haor, tea garden and salt pan. Agriculture land covers 9.5 million hectares in Bangladesh [15]. But researcher also noted that the area of agricultural land decreases day by day in Bangladesh. Among this total land, 8.52 million hectares is under crop land [23]. The shifting rate of agricultural land to non-agricultural use had been reported to be about $1 \%$ per year [24]. The main cause of shifting rate from agricultural land to non-agricultural land is to the faster economic growth and the infrastructure development implied [25].

\subsubsection{Forest Lands}

Major parts of forest were found in Khulna, Bagerhat, Satkhira,Potuakhali, Cox's bazaar, Rangamati, Bandarban, Khagrachari, Gazipur, Tangail, Mymensingh, Rangpur and Sylhet district of Bangladesh. Among them Mangrove covers Khulna, Bagerhat, Satkhira districts (Figure 8). At present, the amount of forest land is 1434136 ha or $9.84 \%$ of total land in Bangladesh and mangrove forest including water of 601,700 hectare, which is $4.07 \%$ of total land mass of the country. However, forest area has decreased at the rate of $0.538 \%$ annually from 1976 to 2010 but the annual rate of increasing mangrove area was $0.01 \%$ during the period 1976 to 2000. This increase of mangrove forest may be due to mangrove 


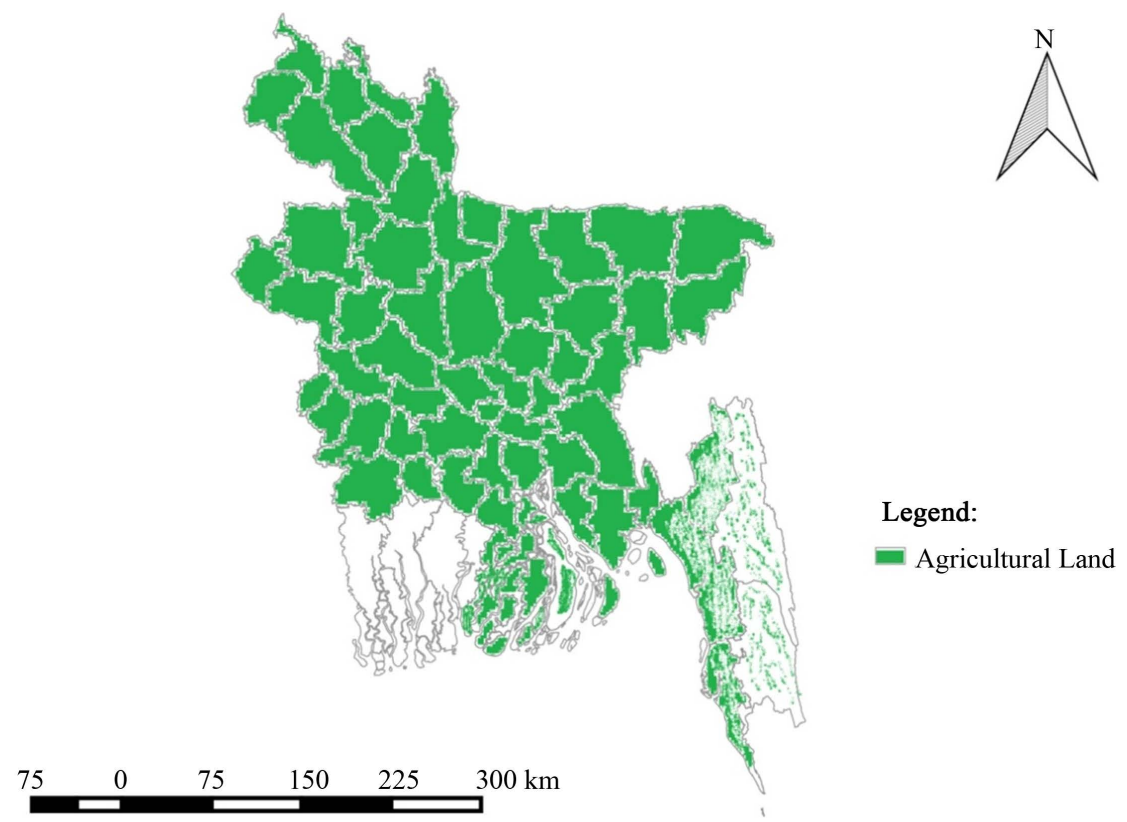

Figure 7. Land area used as agricultural activities in Bangladesh.

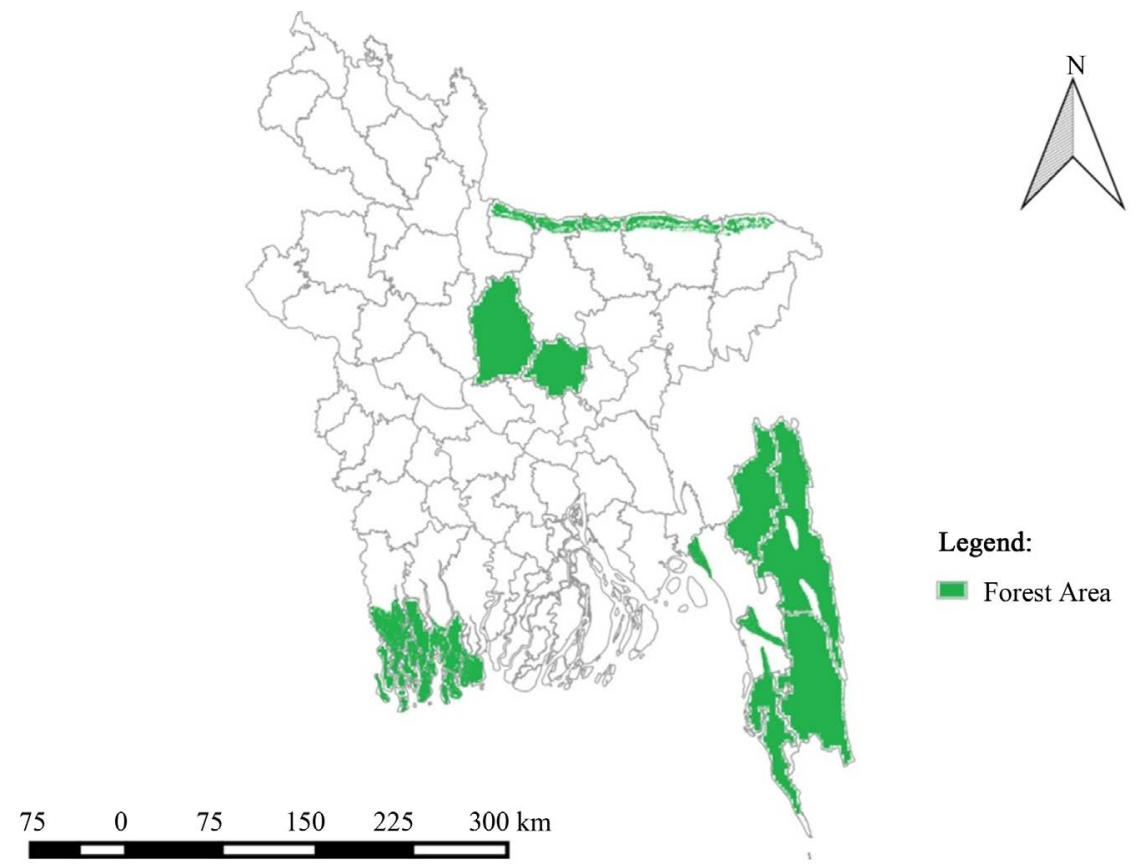

Figure 8. Present status of forest area in all over Bangladesh.

plantation to 132,000 ha of land along the shore land of coastal districts up to 2000 [26]. Forest cover area in Bangladesh remained almost stable during the period from 1990 to 2005 and modified natural forest area was in decreasing trend, while tree plantations are increasing to offset the decrease [22].

\subsection{General Soil Type}

Soils are generally classified into 20 soil types based on formation and appear- 
ance of the soils. There are 14 general soil types have been identified on floodplain areas, five on terraces, and one on hilly areas. Non-calcareous grey floodplain soils occupy about one-fourth of the total area of Bangladesh. About 44\% of the total land area of Bangladesh covered Non-calcareous dark grey and calcareous dark grey floodplain soils.

\subsubsection{Calcareous Soil}

It was found that Faridpur,Noakhali and Chittagong districts had calcareous alluvium soils types. Dhaka, Mymensingh, Faridpur, Rajshakhi and Pabna district had calcareous brown floodplain soils. Sylhet, Barisal, Jessore and Faridpur districts had calcareous grey floodplain soils and Rajshahi district hadcalcareous dark grey floodplain soils in the study area. Calcareous soil areas are shown in the map below (Figure 9). Calcareous alluvium on the active Ganges floodplain mainly comprises brownish grey to pale brown sandy and silty deposits. Calcareous alluvium soils are located in some of the upazilas of Faridpur, Noakhali and Chittagong districts. It has covered $5918 \mathrm{~km}^{2}$ of land area in our country which show $4.1 \%$ of the total land area. Calcareous brown floodplain soils have been found on highest ridges and near riverbanks. Calcareous brown floodplain soils are located in some of the upazilas of Dhaka, Mymensingh, Faridpur, Rajshahi and Pabna districts. It has covered $14,347 \mathrm{~km}^{2}$ of land area in our country which show $9.9 \%$ of the total land area [27].

\subsubsection{Non-Calcareous Soil}

It was found that major parts of Mymensingh, Rangpur, Bogra and Pabna districts had non-calcareous alluvium soils. Mymensingh and Dinajpur districts had non-calcareous brownfloodplain soils.Bogra, Chittagong, Mymensingh,

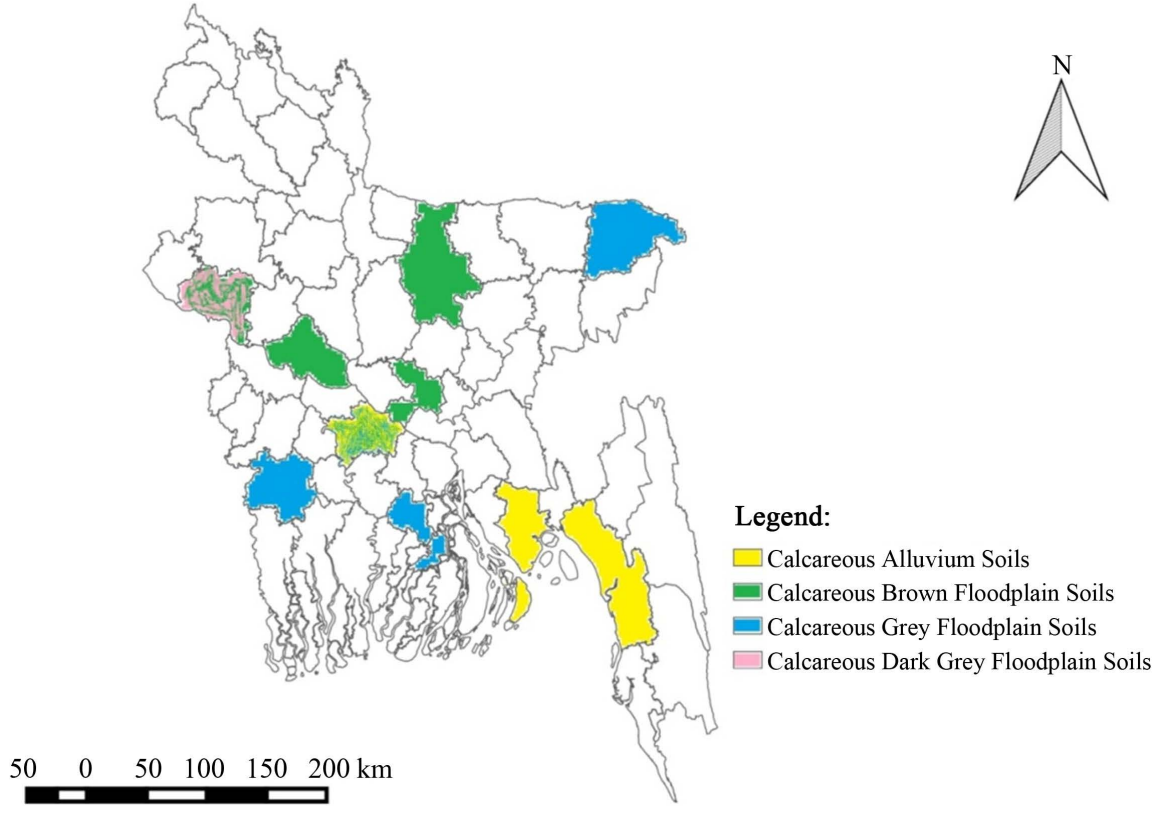

Figure 9. Variation among calcareous types soil in Bangladesh. 
Sylhet, Rangpur and Dinajpur districts hadnon-calcareous grey floodplain soils and Dhaka, Faridpur, Kishoreganj, Mymensingh and Noakhali districts had noncalcareous dark grey floodplain soils in the study area. Non-calcareous soil areas are shown in map (Figure 10). Non-calcareous alluvium soils occupy extensive areas on the active Tista and Brahmaputra-Jamuna floodplains. Noncalcareous alluvium soils are located in some of the upazilas of Mymensingh, Rangpur, Bogra and Pabna districts. It has covered $5622 \mathrm{~km}^{2}$ of land area in our country which show $3.9 \%$ of the total land area. The agricultural potential of non-calcareous brown floodplain soils is mainly moderate to low. Non-calcareous brown flood plain soils are located in some of the upazilas of Mymensingh and Dinajpur district. It has covered $15,996 \mathrm{~km}^{2}$ of land area in our country which show $11 \%$ of the total land area [27].

\subsubsection{Terrace Soil}

In the study area deep grey terrace soils were found in the major parts of Bogra, Dinajpur, Mymensingh, Rajshahi, Pabna, Jamalpur and Joypurhat districts. Shallow grey terrace soilswere found inBogra, Dinajpur, Jamalpur, Joypurhat, Rangpur, Pabna and Narayangong districts. Brown mottled terrace soils were found in Bogra, Dinajpur, Jamalpur, Joypurhat, Narayangong, Rajshahi, Pabna and Rangpur districts. Deep red brown terrace soilswere found inBogra, Dinajpur, Jamalpur, Joypurhat, Narayangong, Rajshahi, Pabna and Rangpur districts and shallow red brown terrace soils were found in Dhaka, Mymensingh, Comilla, Rajshahi, Dinajpur andRangpur districts (Figure 11). Deep grey terrace soils are located in some of the upazilas of Bogra, Dinajpur, Jamalpur, Joypurhat, Mymensingh, Pabna and Rajshahi districts. These soils have low agricultural potential for both dry land crops and for paddy cultivation. Brown mottled

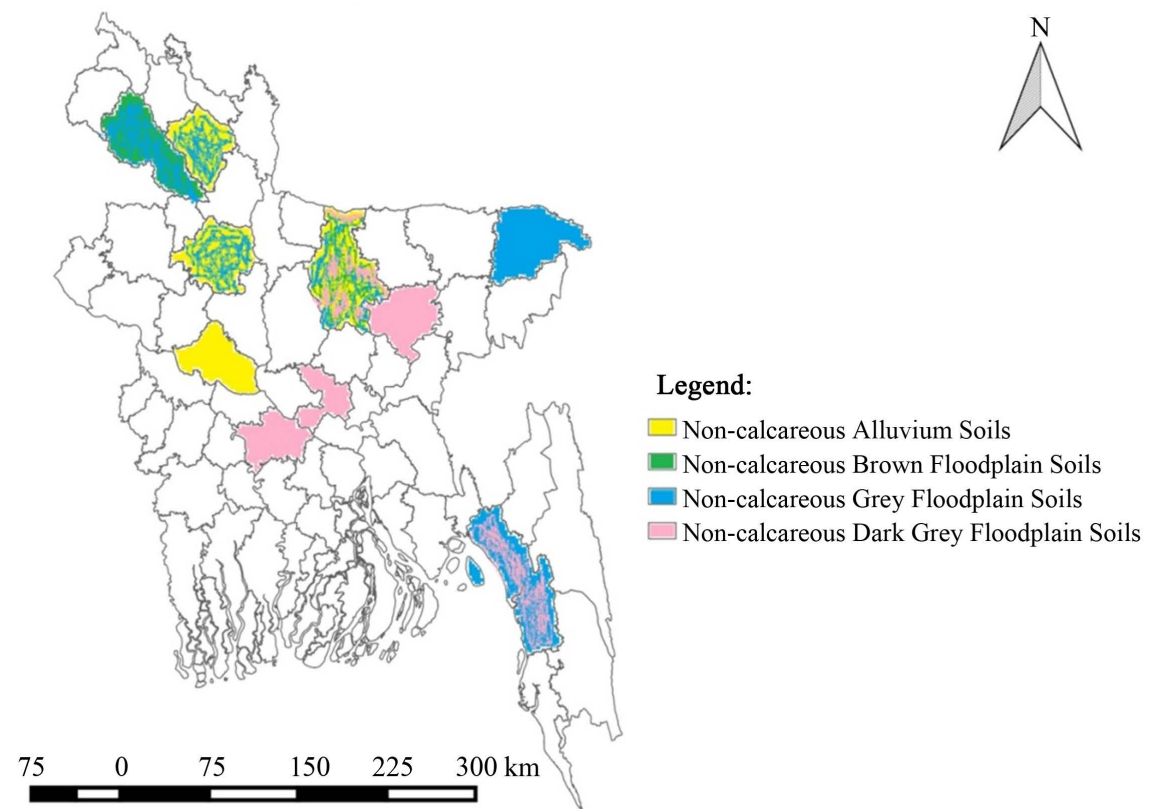

Figure 10. Showing different types of non-calcareous soil in the Bangladesh. 


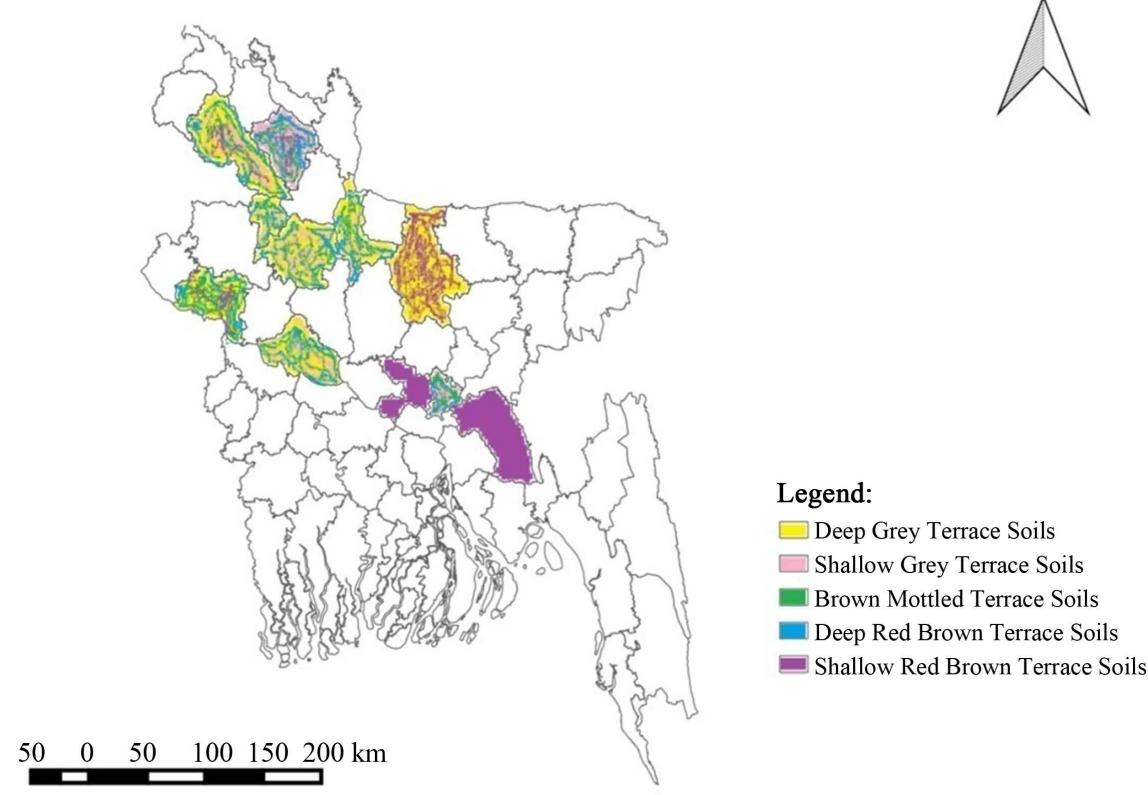

Figure 11. Different types of terrace soil in Bangladesh using Q-GIS mapping.

terrace soils are located in some of the upazilas of Bogra, Dinajpur, Jamalpur, Joypurhat, Narayanganj, Pabna, Rajshahi and Rangpur districts. It has covered $342 \mathrm{~km}^{2}$ of land area in our country mostly available in the Madhupur tract and Akhaura terrace. Deep red brown terrace soils are located in some of the upazilas of Bogra, Dinajpur, Jamalpur, Joypurhat, Narayanganj, Pabna, Rajshahi and Rangpur districts [27].

\subsubsection{Grey Soil}

It was found that major parts of Chittagong, Noakhali, Comilla and Sylhet districts had grey piedmont soils and Bogra, Dinajpur, Jamalpur, Joypurhat, Narayangong, Rajshahi, Pabna and Rangpur districts had grey valley soils in the study area. Grey soil areas are shown in the map below (Figure 12). Grey piedmont soils are located in some of the upazilas of Chittaong, Noakhali, Comilla and Sylhet district. It has covered $2053 \mathrm{~km}^{2}$ of land area in our country which show $1.15 \%$ of the total land area. Grey soils observed in the shallow of the Madhupur and Barind regions, shown in Figure 12. This type of soils has less potentiality in crop production in Bangladesh mostly. Grey valley soils are located in some of the upazilas of Bogra, Dinajpur, Jamalpur, Joypurhat, Narayanganj, Pabna, Rajshahi and Rangpur districts. It has covered $1143 \mathrm{~km}^{2}$ of land area in our country which show $0.8 \%$ of the total land area [27].

\subsubsection{Black Terai, Peat and Hill Soils}

In the study area black terai soils were found in Dinajpur district. Peat soils were found in Barisal, Faridpur, Gopalgong, Sylhet and Jessore district. Hill soils were found in Kishoreganj, Mymensingh, Chittagong, Noakhali, Comilla and Sylhet districts. Black terai, peat and hill soil areas are shown in the map (Figure 13). 


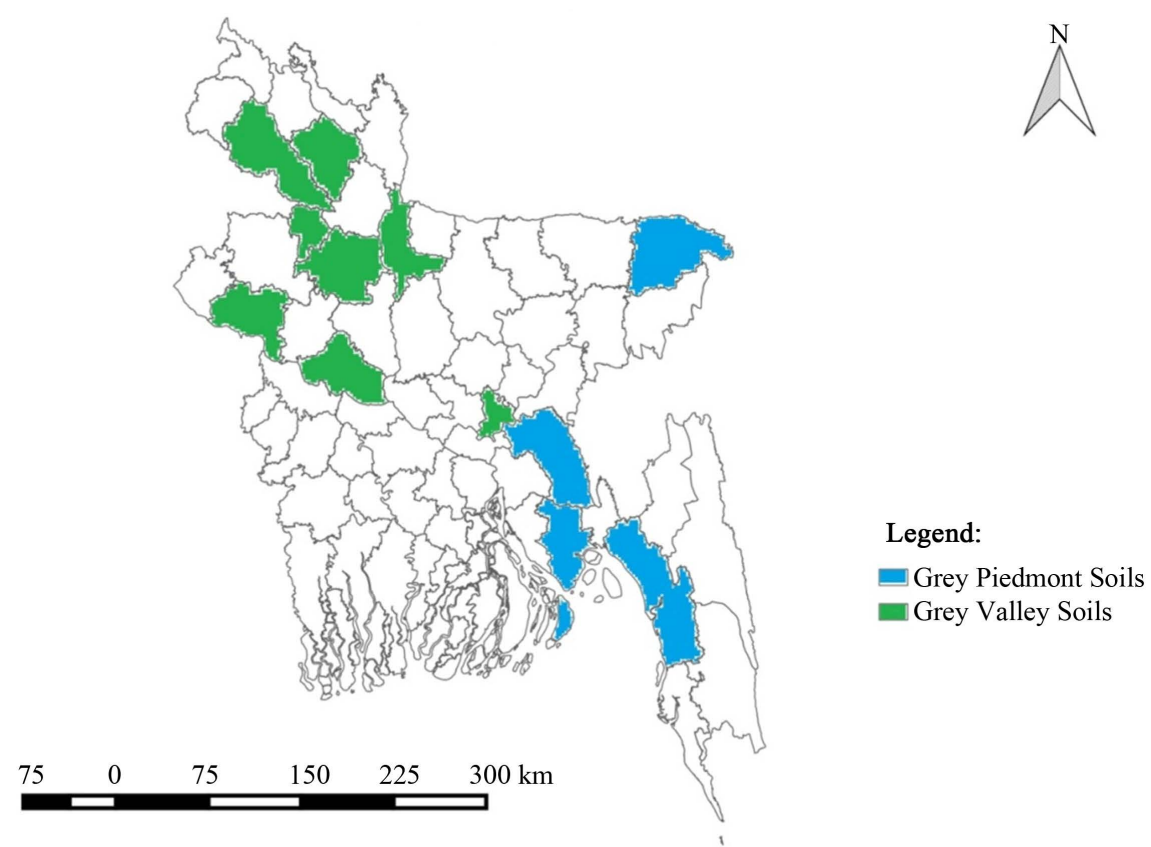

Figure 12. Status of different categories of gray soil in Bangladesh.

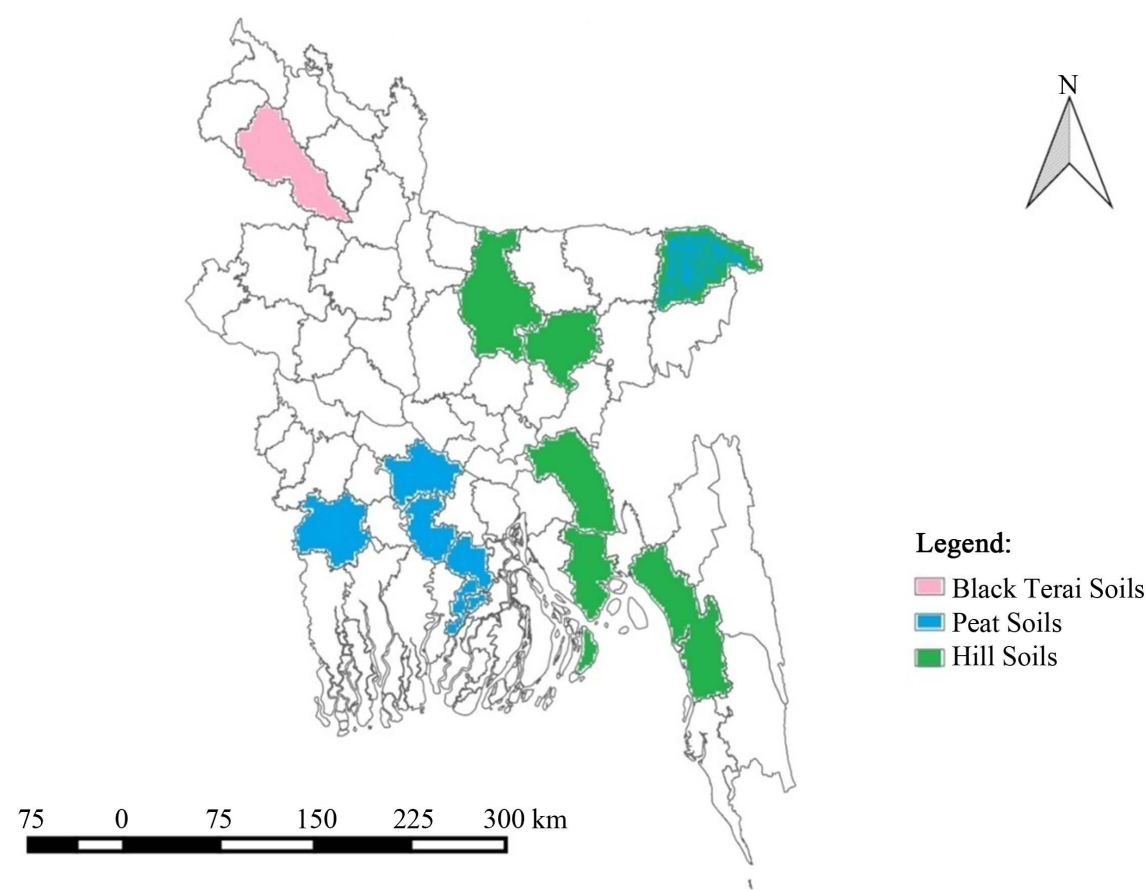

Figure 13. Showing area covered by black terai, peat and hill soils in Bangladesh.

Black terai soils are located in some of the upazilas of Dinajpur district. This type of soils has also less potentiality in agricultural production. It has covered 834 $\mathrm{km}^{2}$ of land area in our country which show $0.6 \%$ of the total land area. Peat soils extensively recorded in the beels located in Gopalganj and Khulna districts. In some haors of the Sylhet basin in Bangladesh peat soils noted. Peat soils are located in some of the upazilas of Faridpur, Gopalganj, Sylhet, Barisal and Jes- 
sore. Brown hill soils are located in some of the upazilas of Kishoreganj, Mymensingh, Chittagong, Noakhali, Comilla and Sylhet districts. It has covered $15,615 \mathrm{~km}^{2}$ of land area in our country which show $10.8 \%$ of the total land area [27].

\subsubsection{Acid Soils}

It was found that major parts of Kishoreganj, Pabna, Rajshahi, Dhaka, Comilla and Sylhet districts had acid basin clays and Khulna and Chittagong districts had acid sulphate soils (Figure 14). Acid basin clays soils observed mostly in Punarbhaba floodplain, Atrai basin, Arial bel, Sylhet basin. There are not significant important role of acid basin clays soils in agricultural production. Acid basin clays soils are located in some of the upazilas of Dhaka, Kishoregonj, Comilla, Sylhet, Rajshahi and Pabna district in Bangladesh. These soils occur in few south western parts of Bangladesh. Acidic sulphate soils are severely limited for agricultural activities. Acid sulphate soils are located in some of the upazilas of Khulna and Chittagong district. It has covered $2266 \mathrm{~km}^{2}$ of land area in our country which show $1.6 \%$ of the total land area [27].

\section{Conclusions}

The total area of Bangladesh was divided into three categories. These were highland, medium highland and low land. Highland, medium highland and low land covered 29\%, 35\% and 21\% of the total land in Bangladesh, respectively. Others $15 \%$ land covers by river, urban and homesteads etc. About $99 \%$ areas of the Chittagong hill tract and Bandarban were belonging to high land category. The major part of Bangladesh had medium high land which is very much preferable

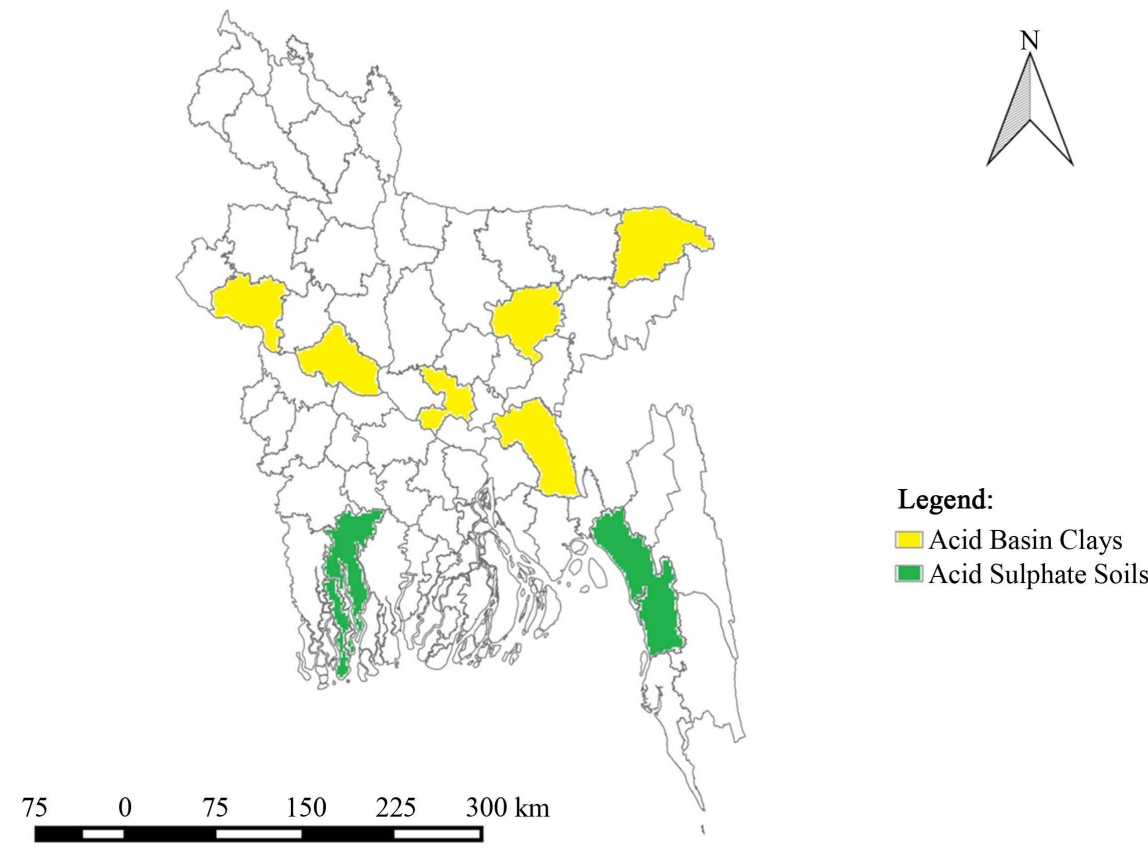

Figure 14. Showing distribution of acid soils in Bangladesh. 
to agriculture. This study was illustrated by different maps where most part of Bangladesh consists of agricultural land along with haors, baors and beels. Major parts of forest were found in Khulna, Bagerhat, Satkhira, Potuakhali, Cox's Bazaar, Rangamati, Bandarban, Khagrachari, Gazipur, Tangail, Mymensingh, Rangpur and Sylhet district of Bangladesh. Mangrove forest was found in Khulna, Bagerhat and Satkhira district in Bangladesh. Roughly it was found that, baors and beels were present in south-western region of Bangladesh. On the other hand, haors were located in Sylhet, Sunamgonj, Hobigonj and Moulovibazar district. However, Bangladesh had a natural lake which was located in Rangamati district of hill tract. Kustia, Pabna, Dinajpur, Rangpur, Dhaka, Narayangonj, Khulna, Jessore, Sylhet, Rajshahi, Munshigonj, Norshindi, Comilla, Chittagong were the major urban and industrial zone, and Cox's bazaar and Chittagong districts were the sea salt production zone. It was found that Sylhet, Moulovibazar, Hobigonj, Chittagong and Panchagorh district had a lot of tea garden which provide our country's tea demand. Fourteen types have been identified on floodplain areas, one on hilly areas and rest of them are terrace lands. The agricultural potential of non-calcareous brown flood plain soils were mainly moderate to low and non-calcareous grey floodplain soils were the most extensive soils in the country.

The exploration of mapping of different important parameters of soils in Bangladesh has done using GIS in the present study. Data collection, shape file preparation and finalize the respective maps of various important soil types in Bangladesh etc. are the major steps for this research. With such kind of research it can be concluded that Bangladesh has a very wide diverse quality of soil characteristic with soil formation, texture, $\mathrm{pH}$, salinity, toxicity, soil nutrient, soil land types as well as topography. This research work can be the remarks of the present soil quality and diversity of soil all over the Bangladesh. It would be helpful to explore the overall situation of different soil types and their important properties through distinguished maps.

\section{References}

[1] Hossain, M.S., Chowdhury, S.R., Das, N.G., Sharifuzzaman, S.M. and Sultana, A. (2008) Integration of GIS and Multicriteria Decision Analysis for Urban Aquaculture Development in Bangladesh. Landscape and Urban Planning, 90, 119-133. https://doi.org/10.1016/j.landurbplan.2008.10.020

[2] Allen, J.S. and Potts, T.D. (2002) A GIS Based Analysis and Prediction of Parcel Land Use Change in a Coastal Area. World Congress on Coastal and Marine Area, Vancouver, British Columbia, Canada.

[3] Fung, T. (2007) An Assessment of TM Imagery for Land Cover Change Detection. IEEE Transactions on Geoscience and Remote Sensing, 28, 681-84. https://doi.org/10.1109/TGRS.1990.572980

[4] Chowdhury, A.H. (2002) To Study the Physical and Chemical Properties of Two AEZ of Bangladesh under Three Cropping Patterns. M.Sc. Thesis. Department Soil Science, Bangladesh Agricultural University, Mymensingh.

[5] Haque, A.K.M.S. (2001) Evaluation of Physical Properties of Some Soils of a Land 
Development Unit in Bangladesh. M.Sc. Thesis, Department Soil Science, Bangladesh Agricultural University, Mymensingh.

[6] Islam, M.S. (2003) Soil Management in Agricultural Research in Bangladesh. Bangladesh Agricultural Research Council, Dhaka, Bangladesh, 105-109.

[7] Islam, M.A., Akhtar, D. and Farukh, M.A. (2017) Q-GIS Mapping to Explore the Status of Quality of Drinking Water in Bangladesh. IOSR Journal of Environmental Science, Toxicology and Food Technology (IOSR-JESTFT), 11. (In Press)

[8] Khan, Z.H., Mazumder, A.R., Mohiuddin, A.S.M., Hussain, M.S. and Saheed, S.M. (2000) Physical Properties of Some Benchmark Soils from the Floodplains of Bangladesh. Journal of Indian Social Soil Science, 46, 442-446.

[9] Azad, A.K. (2000) A Study of Some Physical and Chemical Properties of Saline and Non-Saline Soils of Bangladesh. M.Sc. Thesis, Department of Soil Science, Bangladesh Agricultural University, Mymensingh.

[10] Mollah, K.U. (2005) State of Physical Properties of Soils Placed under Intensive Cropping in Madhupur Tract of Bangladesh. M.Sc. Thesis. Department of Soil Science, University of Dhaka, Bangladesh.

[11] Rahman, M.M. (2006) Puddling Effects by Differential Tillage on Soil Physical Properties, Root Growth and Yield of Rainfed Rice. M.Sc. Thesis, Department of Soil Science, Bangladesh Agricultural University, Mymensingh.

[12] Ali, A.M.S. (2006) Rice to Shrimp: Land Use/Land Covers Changes and Soil Degradation in South-Western Bangladesh. Land Use Policy, 23, 421-435. https://doi.org/10.1016/j.landusepol.2005.02.001

[13] Joshua, W.D. and Rahman, M. (2003) Physical Properties of Soil on the Tista River Floodplain and Barind Tract of Bangladesh. Soil Resource Development Institute, Dhaka, 13-40.

[14] Mondal, M.Y.A. (2000) Studies on the Physical Properties of BAU Farm Soil. M.Sc. Thesis, Department of Soil Science, Bangladesh Agricultural University, Mymensingh.

[15] SRDI (Soil Resources Development Institute) (2010) Land and Soil Resources Utilization. DistrictNirdeshika Series-Jhalokhati. SRDI, Dhaka, 61-70.

[16] Sood, R.D. and Kanwar, B.S. (2000) Distribution of Organic and Total Phosphorus in Some Soil Profiles of Different Agro Climatic Zones of Himachal Pradesh. Journal of Indian Social Soil Science, 34, 404-406.

[17] Sahoo, A.K., Sah, K.D. and Gupta, S.K. (2005) Organic Carbon Status in the Sunderbans Mangrove Soils. Journal of Indian Social Soil Science, 43, 265-267.

[18] Bhuiyan, N.J. (2008) Co-Ordinated Project on Potassium Studies Progress Report. Bangladesh Rice Research Institute, Joydebpur, Dhaka, 1-45.

[19] Hossain, A. (2009) To Study the Physical Parameters of Different Soil Series of Haluaghat Upazila. M.Sc. Thesis, Department of Soil Science, Bangladesh Agricultural University, Mymensingh.

[20] Anwar, M.K. (2003) Evaluation of Some Physico-Chemical Characteristics of Saline Soil. M.Sc. Thesis, Department of Soil Science, Bangladesh Agricultural University, Mymensingh.

[21] Wahida, M. (2000) Soil Chemical Analysis. M.Sc. Thesis, Department of Soil Science, University of Dhaka, Dhaka.

[22] FAO (Food and Agricultural Organization) (2013) Agro Ecological Regions of Bangladesh, 2, 530-570. 
[23] BBS (Bangladesh Bureau of Statistics) (2015) Yearbook of Agricultural Statistics of Bangladesh. Bangladesh Bureau of Statistics, Dhaka.

[24] UNDP (United Nation Development Program) (2013) Center for Environmental and Geographic Information Services, Dhaka.

[25] Rahman, M.T. and Hasan, M.N. (2003) Assessment of Shifting of Agricultural Land to Non-Agricultural Land in Bangladesh. SRDI, Dhaka.

[26] BFD (Bangladesh Forest Department) (2011) Ministry of Environment and Forest. Government of Bangladesh, Dhaka.

[27] Banglapedia (2016) The National Encyclopedia of the People's Republic of Bangladesh. 